\title{
Comparison of Transvaginal Ultrasound versus MRI Finding of Previous Lower Segment Caesarean Scar Patient Undergoing Repeat LSCS
}

Dr. Deepak KS ${ }^{1}$, Dr. Bharat $\mathrm{MP}^{2 *}$, Dr Dhruva $\mathrm{R}^{3}$

${ }^{1,2}$ Associate Professor, Department of Radiodiagnosis, Subbaiah Institute of Medical Sciences, Shimoga, Karnataka, India
${ }^{3}$ Assistant Professor, Department of Radiodiagnosis, Subbaiah Institute of Medical Sciences, Shimoga, Karnataka, India

\section{Article History}

Received: 25.11.2020

Accepted: 09.12.2020

Published: 12.12 .2020

Journal homepage: https://www.easpublisher.com

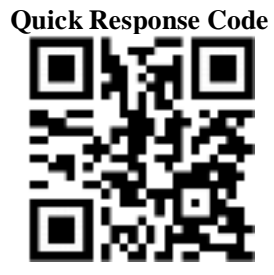

\section{Abstract: Background: Ultrasound is used to evaluate the LUS, especially if there is a} previous scar, and it is more beneficial to predict the possibility of the occurrence of any complications during labor either by repeated cesarean section or by vaginal delivery. Material and Methods: A total of 50 pregnant patients were included in this study conducted at Subbaiah Institute of Medical Sciences from January 2020 - August 2020. Transabdominal ultrasound was done for scarred uteri. Sonographic findings were co-related with introperative findings. All the given data were entered on SPSS version 23. Age was expressed as mean \pm SD. Parity, gestational age, and interval between cesarean sections were expressed as frequencies with percentages. Statistical analysis was done by using Chisquare test for categorical data for association between sonographic scar thickness and intraoperative findings. The statistical significance was set at p-value e $<0.05$. Results: The mean age of study group was $28.27 \pm 3.32$ years. The minimum age was 18 years and maximum was 39 years. Maximum number of patients (65\%) had 13-24 months interval between previous and current pregnancy. No patient had interval more than 48 months. The mean scar thickness in study group was $3.24 \mathrm{~mm} \pm 1.3 \mathrm{~mm}$. Minimum scar thickness on TVS was $1.2 \mathrm{~mm}$ and maximum was $6 \mathrm{~mm}$. Among all, maximum (34.0\%) number of patients had scar in range of 3.1-4.0 mm. Mean scar thickness on MRI was $3.6 \mathrm{~mm} \pm 1.23$ $\mathrm{mm}$. Minimum scar thickness measured on MRI seen was $1.7 \mathrm{~mm}$ maximum thickness measured was $5.6 \mathrm{~mm}$. Similar to TVS findings maximum (32.0\%) patients had scar thickness seen in range of 3.1-4.0 mm. In $82.0 \%$ cases scar was intact and scar thickness was measured using calliper while in $14 \%$ cases scar was dehiscent. Conclusion: MRI offers no advantage in diagnostic accuracy for the measurement of LSCS scar thickness during consideration of TOLAC.

Keywords: Transvaginal Ultrasound, MRI, Caesarean Scar.

Copyright (C) 2020 The Author(s): This is an open-access article distributed under the terms of the Creative Commons Attribution 4.0 International License (CC BY-NC 4.0) which permits unrestricted use, distribution, and reproduction in any medium for non-commercial use provided the original author and source are credited.

\section{INTRODUCTION}

Lower segment cesarean section (LSCS) rates are rising throughout the world [1]. Women with previous one cesarean can undergo either the trial of vaginal birth or elective repeat cesarean section in their next pregnancy [2]. Uterine scar dehiscence is one of the complications associated with previous LSCS, in which there is disruption and separation of previous scar. The incidence reported for uterine scar dehiscence was between 0.2-4.3percent of all pregnancies associated with previous cesarean section [3]. A successful vaginal birth after cesarean (VBAC) is associated with fewer complications than an elective repeat cesarean section. However, elective repeat LSCS is better to be done than failed trial of labor after LSCS [4].

Advantages of VBAC include avoidance of major abdominal procedure, decrease risk of postpartum hemorrhage, and purpeural infections and reduction in the recovery time after delivery [5]. It also reduces the further risk of repeat cesarean section, lessen the chances of cesarean hysterectomy, bowel and bladder damage, and need for blood transfusion and abnormal placental conditions in future, e.g. placenta previa and placenta accreta [6]. Disadvantages of VBAC are risk of uterine rupture due to dehiscence of previous cesarean section scar. It can be life-threatening due to excessive hemorrhage. There are different methods to check the integrity of previous cesarean section scar [7]. These include postoperative echographic evaluation of uterine wound, interval hysterography, and MRI imaging. Ultrasonography can be used to check the integrity of previous scar; and it can be helpful in the prediction of uterine rupture during labour, and detect the lower uterine thickness [8].

The lower uterine segment (LUS) thickness is categorised into 4 grades [9]. Grade 1 is a well formed LUS. Grade 2 is a thin uterine scar but no uterine 
contents are visible. Grade 3 is scar dehiscence. Grade 4 is dehisced or ruptured scar. Different studies had given varying cut-off values for the safe trial of VBAC, but still there is no consensus on a safe limit. The cut-off value of LUS scar thickness in different studies range between 2-3.5 mm, above which the chances of uterine rupture during labour is less likely [10]. Factors associated with uterine scar rupture during labour include number of LSCS, inter-delivery interval, prior vaginal delivery, age of the mother, gestational age at delivery, and birth weight [11].

The objective of the present study was to find out the association between scar thickness, assessed sonographically and MRI.

\section{OBJeCTIVES}

The main aim of this study was to compare MRI and TVS in measurement of the thickness of the LUS at term to determine which method is the most accurate and more reliable to measure LUS by comparing the measurement obtained by each method separately with the actual thickness obtained intraoperatively.

\section{Materials AND Methods \\ Study Design}

Prospective observational comparative study Sample size-50

\section{Study procedures}

Patients were recruited from the Department of OBGY and conducted at Department of Radiology, Subbaiah Institute of Medical Sciences, period of eight months from January 2020 - August 2020 with sample size-50 patients.

\section{Inclusion criteria}

1. Patients with previous one lower segment cesarean section and willing for study of labour after birth

2. Patients with previous one lower segment cesarean with no $\mathrm{H} / \mathrm{O}$ previous vaginal birth.

\section{Exclusion criteria}

1. Patients with multiple pregnancies, preterm deliveries, polyhydramnios or oligohydramnios, low lying placenta, patients with history of uterine surgery other than cesarean section or unavailable previous caesarian details, and having a contraindication to MRI were excluded from the study.

Patients who fulfilled inclusion criteria were recruited in study after informed written consent and assessed at 24-28 weeks period of gestation. Detailed obstetric $\mathrm{H} / \mathrm{O}$ of all previous conception and previous cesarean section which included preoperative, intraoperative and post-operative complications noted.

Routine obstetric examination done at 36-37 weeks POG. A detailed obstetric ultrasound was performed. Patients before undergoing elective repeat lower segment cesarean section had Transvaginal ultrasonography and MRI for evaluation of previous cesarean uterine scar.

The transvaginal sonography and MRI for uterine lower segment scar thickness measurement done at 37 weeks period of gestation. TVS performed on $5 \mathrm{MHz}$ to $9 \mathrm{MHz}$ transvaginal transducer of $\mathrm{HD} 11$ Philips USG machine and GE Voluson E8 USG machine. The scar/lower uterine segment was seen juxtaposed to the bladder. Measurements taken at 3 sites of lower uterine segment to minimize error and average of 3 readings taken as scar thickness.

A comprehensive scan of lower uterine segment in various planes was done to look for any asymptomatic uterine dehiscence. MRI of all patients done on 1.5 Tesla magnet (Avantis and Phillips Acheiva) using CP array surface coil. T1W and T2W sequences were obtained in sagittal and axial plane. The thinnest portion of the lower uterine segment was considered to be scar and its measurement taken in sagittal plane.

\section{Statistical Analysis}

Statistical analysis was performed using SPSS software. The mean scar thickness derived by each modality was stratified according to the surgical grades assigned during surgery. The significance of difference in mean between normal and abnormal scars was evaluated using t-test. Intraclass correlation coefficient analysis was also used to quantify the agreement between the scar thicknesses measured by both the modalities.

\section{RESUlTS}

The distribution of population on basis of age and educational status depicted below in table 1 . The mean age of study group was $28.27 \pm 3.32$ yrs. The minimum age was 18 years and maximum was $39 \mathrm{yr}$. Frequency distribution on basis of interval between previous caesarean and current pregnancy depicted below in [Table 1]. Maximum number of patients (65\%) had 13-24 months interval between previous and current pregnancy. No patient had interval more than 48 months. 
Table-1: Baseline characteristics of the study population $(\mathrm{N}=50)$

\begin{tabular}{|l|l|}
\hline Variables & Numbers (\%) \\
\hline Age in years & \\
$<20$ & $0(0.0)$ \\
$20-24$ & $18(36.0)$ \\
$25-29$ & $22(44.0)$ \\
$\geq 30$ & $10(20.0)$ \\
\hline Educational status & \\
Illiterate & $4(8.0)$ \\
Primary & $5(10.0)$ \\
Secondary & $8(16.0)$ \\
Senior secondary & $13(26.0)$ \\
Graduate & $15(30.0)$ \\
Post-graduate & $5(10.0)$ \\
\hline Socio-economic & \\
status Upper class & $2(4.0)$ \\
Upper middle class & $13(26.0)$ \\
Lower middle class & $12(24.0)$ \\
Upper lower class & $16(32.0)$ \\
Lower class & $7(14.0)$ \\
\hline Interval between previous caesarean and current pregnancy (months) & \\
$\leq 12$ & $4(8.0)$ \\
$13-24$ & $32(64.0)$ \\
$25-36$ & $10(20.0)$ \\
$37-48$ & $4(8.0)$ \\
$>48$ & $0(0.0)$ \\
\hline
\end{tabular}

Table-2: Table showing scar thickness and characteristics on transvaginal ultrasonography and MRI (N=50)

\begin{tabular}{|l|l|}
\hline Scar Thickness $(\mathbf{m m})$ & Number $(\%)$ \\
\hline On transvaginal ultrasound & $7(14.0)$ \\
$1-2$ & $11(22.0)$ \\
$2.1-3$ & $17(34.0)$ \\
$3.1-4$ & $10(20.0)$ \\
$4.1-5$ & $5(10.0)$ \\
$5.1-6$ & \\
\hline On MRI & $4(8.0)$ \\
$1-2$ & $10(20.0)$ \\
$2.1-3$ & $16(32.0)$ \\
$3.1-4$ & $15(30.0)$ \\
$4.1-5$ & $5(10.0)$ \\
$5.1-6$ & \\
\hline Intra-operative scar thickness measured by caliper & \\
Intact & $41(82.0)$ \\
Rupture & $2(4.0)$ \\
Dehiscent & $7(14.0)$ \\
\hline
\end{tabular}

Scar thickness was measured on transvaginal sonography by taking 3 reading to minimize the measurement error. The mean scar thickness in study group was $3.24 \mathrm{~mm} \pm 1.3 \mathrm{~mm}$. Minimum scar thickness on TVS was $1.2 \mathrm{~mm}$ and maximum was $6 \mathrm{~mm}$. Among all, maximum $(34.0 \%)$ number of patients had scar in range of 3.1-4.0 $\mathrm{mm}$ [Table 2]. Mean scar thickness on MRI was $3.6 \mathrm{~mm} \pm 1.23 \mathrm{~mm}$. Minimum scar thickness measured on MRI seen was $1.7 \mathrm{~mm}$ maximum thickness measured was $5.6 \mathrm{~mm}$. Similar to TVS findings maximum $(32.0 \%)$ patients had scar thickness seen in range of 3.1-4.0 $\mathrm{mm}$ [Table 2].
Table-3: Distribution of scar thickness and assessment by TVS and MRI $(\mathbf{N = 5 0})$.

\begin{tabular}{|l|l|l|}
\hline \multirow{2}{*}{ Scar thickness (mm) } & \multicolumn{1}{|l|}{ TVS } & MRI \\
\cline { 2 - 3 } & N (\%) \\
\hline $1-2$ & $7(14.0)$ & $4(8.0)$ \\
\hline $2.1-3$ & $11(22.0)$ & $10(20.0)$ \\
\hline $3.1-4$ & $17(34.0)$ & $16(32.0)$ \\
\hline $4.1-5$ & $10(20.0)$ & $15(30.0)$ \\
\hline $5.1-6$ & $5(10.0)$ & $5(10.0)$ \\
\hline
\end{tabular}

*7 patients were excluded as 6 had scar dehiscence and one had scar rupture. In these 7 patients, scar thickness was not measured. Scar rupture seen in $2.5 \%$ case. Frequency distribution of scar thickness in between transvaginal sonography and intra-operative 
findings given [Table 3]. Similarly, frequency distribution of scar thickness between MRI and intraoperative findings given in [Table 3].

Table-4: Pearson's correlation coefficient between TVS, MRI and intra-operative caliper measurement for scar thickness

\begin{tabular}{|l|l|}
\hline TVS \& MRI & $\mathbf{+ 0 . 9 7 3}$ \\
\hline TVS and intra-operative thickness & +0.735 \\
\hline MRI and intra-operative thickness & +0.532 \\
\hline
\end{tabular}

The linear correlation coefficient depicted between 3 modalities to measure scar thickness is given in [Table 4]. We found that there is positive correlation between all three modalities i.e. TVS, MRI and intraoperative findings.

\section{DisCUSSION}

The uterus plays an important role during pregnancy and parturition. Sonography has proven to be a useful modality to determine whether abnormalities related to the LUS (such as placenta previa or weak previous cesarean section scar) are present, thus decreasing fetal and maternal mortality and morbidity [12]. Ultrasonographically, the LUS appears as a twolayered structure that consists, from the urinary bladder inward, of the echogenic visceral-parietal reflection, including the musculosa and mucosa of the urinary bladder (the outer layer), and the relatively hypoechoic myometrial layer [13].

In most clinical settings, especially in the developing world, booking right at the initiation is not a routine practice, as most patients seek support from local midwifery services. Such patients report to proper medical centers only during the third trimester [14]. In such circumstances, the residual myometrium is quite thin and is difficult to measure, but still remains the most useful method to assess the likelihood of scar dehiscence [15]. USG has been labelled as the most optimal method to assess post-cesarean scar thickness with a threshold of $3.5 \mathrm{~mm}$ [16]. The measurements done by USG, however, show poor interobserver reproducibility in few studies, and the sonographic technique for the purpose has been shown to have a shallow upstroke on the learning curve; hence, the same are not predictive for the risk of scar dehiscence in an individual woman [17]. MRI, on the other hand, may have a better reproducibility and can be evaluated by many observers once the images have been acquired [18].

The mean scar thickness was $3.23 \mathrm{~mm} \pm 1.01$ mm. $14 \%$ had $1-2 \mathrm{~mm}$ scar thickness, $22 \%$ had 2.1 to $3.0 \mathrm{~mm}, 34 \%$ of patients had scar thickness in 3.1 to 4.0 $\mathrm{mm}, 20 \%$ in 4.1 to $5.0 \mathrm{~mm}$ scar thickness. MRI for assessment of scar thickness in the investigation subjects, the mean scar thickness was $3.53 \mathrm{~mm} \pm 1.23$ $\mathrm{mm}$. The scar thickness was in range of 1 to $2 \mathrm{~mm}$ scar in $8.0 \%$ of patients, 2.1 to $3 \mathrm{~mm}$ in $20 \%, 3.1$ to $4 \mathrm{~mm}$ in $32.0 \%, 4.1$ to $5 \mathrm{~mm}$ in $30 \%, 5.1$ to $6 \mathrm{~mm}$ in $10.0 \%$ scar thickness. According to Palacios et al of scar thickness assessment by MRI and contrasted and ultrasonography detailed USG as better methodology in assessing uterine scar [19]. According to Bacelar et al. assessed uterine scar by MRI in postpartum period and revealed that MRI can be utilized to recognize incomplete or complete uterine dehiscence in postpartum period however it did not assess the antenatal scar thickness in forecasting scar dehiscence during labour [20].

According to Satpathy G, led an examination to assess the precision of prenatal sonography in measuring the lower uterine portion (LUS) thickness in women with previous Cesarean segment and to evlaute the helpfulness of estimating LUS thickness in forecasting the risk of uterine rupture during a preliminary of vaginal birth. The author revlead that sonography grants exact evaluation of the LUS thickness in women with past Cesarean section and consequently can possibly be utilized to predict the risk of uterine rupture during preliminary of vaginal birth [21].

Scar rupture in our study was $4 \%$ and of asymptomatic uterine scar dehiscence identified per operatively was $14 \%$. Scar thickness was estimated intra operatively utilizing caliper in which $36 \%$ patients had $3 \mathrm{~mm}$ and $20 \%$ had $2 \mathrm{~mm}$ thickness. Scar dehiscence was seen in $100 \%$ of patients with scar thickness of $\leq$ $2.5 \mathrm{~mm}$ estimated on TVS. Additionally, Kumar I estimated scar thickness by caliper and discovered measurably critical relationship among USG and actual scar thickness [22]. In present study, incision was given throughout past scar each an actual scar thickness estimation which gave a standard value with which we compared with radiological findingsof pregnancy with a fully-equipped medical facility.

TVS discovered to be preferable over MRI with actual scar thickness. Likewise, the depiction of scar was discovered better on TVS. In this way, TVS being less expensive and better methodology for estimation of scar thickness. In any case, scar integrity during labour not only depends on prelabour thickness as well as on elasticity of scar tissue and its ability to go through pressure.

The intermodality agreement across groups was established by an intraclass correlation coefficient of 0.973 , which signifies a strong level of agreement between the two modalities. USG is currently the modality of choice for the assessment of a post-cesarean scar and would remain as such due to its cost effectiveness, ease of availability, and operability. This result, however, validates the role of MRI for this important clinical indication and in accordance with the justifications given above may establish the role of this modality as a problem-solving tool, if not the initial 
modality of choice. Further, for a beginner, defining a uterine scar by USG may be difficult as the same is usually judged on the basis of a wedge-shaped hypoechoic area at the expected site cesarean section wound [23]. A tailored application of MRI with utilization of specific imaging protocol has been shown to have better contrast resolution than other modalities and can offer optimal contrast resolution for the above described purpose also. Further, with multiparametric capabilities defining a scar may be best done by MRI [24].

\section{Conclusion}

According to the present study, the diagnostic accuracy of USG-derived scar thickness is superior to MRI-derived scar thickness. MRI being an expensive investigation may not replace ultrasound for the measurement of LSCS scar during and after cesarean. However, in isolated cases, MRI may hold promise to suggest the health of a scar due to a higher negative predictive value than USG.

\section{REFERENCES}

1. Lumbiganon, P., Laopaiboon, M., Gülmezoglu, A. M., Souza, J. P., Taneepanichskul, S., Ruyan, P., \& Bang, H. T. (2010). Method of delivery and pregnancy outcomes in Asia: the WHO global survey on maternal and perinatal health 2007-08. The Lancet, 375(9713), 490-499.

2. Villar, J., Carroli, G., Zavaleta, N., Donner, A., Wojdyla, D., Faundes, A., \& Valladares, E. (2007). Maternal and neonatal individual risks and benefits associated with caesarean delivery: multicentre prospective study. Bmj, 335(7628), 1025.

3. Souza, J. P., Gülmezoglu, A. M., Lumbiganon, P., Laopaiboon, M., Carroli, G., Fawole, B., \& Ruyan, P. (2010). Caesarean section without medical indications is associated with an increased risk of adverse shortterm maternal outcomes: the 2004-2008 WHO Global Survey on Maternal and Perinatal Health. BMC medicine, 8(1), 71.

4. Cheung, V. Y., Constantinescu, O. C., \& Ahluwalia, B. S. (2004). Sonographic evaluation of the lower uterine segment in patients with previous cesarean delivery. Journal of ultrasound in medicine, 23(11), 1441-1447.

5. Rozenberg, P., Goffinet, F., Philippe, H. J., \& Nisand, I. (1996). Ultrasonographic measurement of lower uterine segment to assess risk of defects of scarred uterus. The Lancet, 347(8997), 281-284.

6. Asakura, H., Nakai, A., Ishikawa, G., Suzuki, S., \& Araki, T. (2000). Prediction of uterine dehiscence by measuring Lower uterine segment thickness prior to the onset of labor. Journal of Nippon Medical School, 67(5), 352-356.

7. Michaels, W. H., Thompson, H. O., Boutt, A. N. T. H. O. N. Y., Schreiber, F. R., Michaels, S. L., \& Karo, J.
A. M. E. S. (1988). Ultrasound diagnosis of defects in the scarred lower uterine segment during pregnancy. Obstetrics and gynecology,71(1), 112120.

8. Khursheed, F., Sirichand, P., \& Jatoi, N. (2009). Intraoperative Complications encountered in patients with repeat caesarean section. JLUMHS, 8(01), 76.

9. Awonuga, A. O., Fletcher, N. M., Saed, G. M., \& Diamond, M. P. (2011). Postoperative adhesion development following cesarean and open intraabdominal gynecological operations: a review. Reproductive Sciences, 18(12), 1166-1185.

10. Kushtagi, P., \& Garepalli, S. (2011). Sonographic assessment of lower uterine segment at term in women with previous cesarean delivery. Archives of gynecology and obstetrics, 283(3), 455-459.

11. Rozenberg, P., Goffinet, F., Philippe, H. J., \& Nisand, I. (1996). Ultrasonographic measurement of lower uterine segment to assess risk of defects of scarred uterus. The Lancet, 347(8997), 281-284.

12. Gotoh, H., Masuzaki, H., Yoshida, A. (2000). Predicting incompletre uterine rupture with vaginal sonography during the late second trimester in women with prior cesarean. Obstet Gynecol.

13. Hebisch, G., Kirkinen, P., Haldemann, R., Paakkoo, E., Huch, A., Huch, R. (1994). Comparative study of the lower uterine segment after ceasrean section using ultrasound and magnetic resonance tomography. Ultrasound Med, 15(3):112-6

14. Lijoi, D., Biscaldi, E., Mistrangelo, E., Bogliolo, S., \& Ragni, N. (2006). MRI appearance of the low transverse incision after caesarean section in a symptomatic woman. Eur J Radiology, 59: 133-36.

15. Hoffmann, J., Exner, M., Bremicker, K., Grothoff, M., Stumpp, P., Stepan, H. (2019). Comparison of the lower uterine segment in pregnant women with and without previous cesarean section in 3 T MRI. BMC Pregnancy Childbirth, 19(1):160.

16. Satpathy, G., Kumar, I., Matah, M., Verma, A. (2018). Comparative accuracy of magnetic resonance morphometry and sonography in assessment of postcesarean uterine scar. Indian $J$ Radiol Imaging, 28:169-74

17. Gad, M.S., Abd El Sttar, M.M., Abd, El Gayed, A.M., Mahmoud, N.F. (2015). Evaluation of lower segment cesarean section scar by sonography. Menoufia Med $J$, 28:873-8

18. Cheung, V.Y. (2005). Sonographic measurement of the lower uterine segment thickness in women with previous caesarean section. J Obstet Gynaecol Can, 27(7):674-81.

19. Ebrashy, A., Attia, A., Elshen, E.E., Youseff, D., Abdel, Wahab, W. (2012). Transabdominal versus transvaginal 2D ultrasound in assessment of lower uterine segment thickness in females with previous caesarean section: a comparative study. Kasr Al Aini journal of obstetrics and gynaecology, 3:1-9. 